\title{
Evidenciação de citoqueratina de alto e baixo peso molecular em ceratocisto
}

\author{
Pantelis Varvaki Rados* \\ Manoel Sant'Ana Fo* \\ Joāo Jorge Barbachan* \\ Joana Santos da Luz**
}

\begin{abstract}
RESUMO
Foi realizado o estudo imunocitoquímico de cinco casos de ceratocistos odontogênicos através da marcação de citoqueratinas de baixo peso (Ae1) e alto peso molecular (KAP). Os resultados mostraram uma positividade mais intensa para a citoqueratina nas camadias de células mais próximas a basal.
\end{abstract}

\section{SUMMARY}

The immunocitochemical study of 5 cases of odontogenic keratocists is presented. It was demonstrated the epithelial lining of these cysts was positive for high and low height cytokeratin (KAP) (Ae1). The strongest positivity was for low height cytokeratin (Ae1) and in the inner layer of cells.

\section{UNITERMOS}

Cistos Odontogênicos, Ceratocistos Odontogênicos, Imunocitoquímica.

\section{Introdução}

O ceratocisto ou cisto primordial tem despertado grande interesse desde quando ficou comprovado que o mesmo pode chegar a grandes dimensōes antes de se manifestar clinicamente, e que, o contrário dos outros cistos dos maxilares, tem uma tendência de recidivar após tratamento cirúrgico. Tentando explicar o comportamento clínico de diversas lesōes odontogênicas, a identificação de características microscópicas das mesmas tem sido largamento utilizada $(1,2,3,4,5,6,7,8,10,11,13$, 14).

O nosso objetivo é demonstrar características do revestimento epitelial do ceratocisto quando submetido à coloração com o uso de anticorpos anticitoqueratina de alto e baixo peso molecular.

\section{Revisão da Literatura}

O ceratocisto pode originar-se a partir da lâmina dentária, do órgão do esmalte ou dos restos epiteliais depois da formação do dente (3). A razão para taxas de recidiva tão elevadas permanece obscura. Todavia sugeriu-se que a parede delgada de tecido conjuntivo do cisto pode fazer com que sejam deixados após a remoção fragmentos de epitélio ou cistos satélites. Também relacionou-se com a proliferação cística da camada basal do epitélio bucal suprajacente e com as qualidades biológicas verdadeiras do epitélio cístico. De acordo com REGEZI e SCIUBBA, o índice mitótico das células epiteliais de revestimento do ceratocisto tem sido mostrado como maior do que o de outros cistos odontogênicos, com valores aproximando-se daqueles vistos no componente epitelial do ameloblastoma ou lâmina dentária em crescimento ativo (12).

As citoqueratinas são filamentos intermediários de proteína presentes em todas as células epiteliais. Existem no mínimo dezenove citoqueratinas diferentes, cuja expressão é alterada com o estado diferenciação do tecido. Isto pode ter importância no diagnóstico, e portanto a ex- pressão de citoqueratina pode ter relevância clínica.

GAO et al. encontraram padrōes diferentes de citoqueratina ao comparar cistos odontogênicos com cistos de desenvolvimento através da coloração imunohistoquímica (5).

AGUIRRE et al., estudando ameloblastoma e ceratocisto odontogênico, concluíram que receptores de lecitina encontrados nessas lesōes podem explicar o comportamento biológico das mesmas (1).

A aplicação de imunohistoquímica para o diagnóstico diferencial entre cistos odontogênicos foi questionada por MATTHEWS and BROWNE, uma vez que o perfil de citoqueratina pode ser mascarado pela inflamação ou ceratinização metaplásica (9).

GORDEEFF e CLERGEOU utilizaram anticorpos anticitoqueratina para determinar a natureza do revestimento epitelial de cistos dentígeros e ce-

\footnotetext{
* Professor de Patologia Geral e Bucal da FO/UFRGS e PUC/RS

** Interna da disciplina de Patologia Bucal da FO/UFRGS
} 
ratocistos. Para eles, a confrontação dos resultados desses estudos é difícil em razão das diferenças de protocolo e de materiais utilizados (6).

RADOS et al. utilizaram como marcadores para as ilhas epiteliais no ameloblastoma, as citoqueratinas de alto e baixo peso molecular, encontrando resultados uniformes para ambas, independente do padrão microscópico dos tumores (11).

\section{Materiais e Métodos}

Selecionaram-se cinco casos de ceratocisto, diagnosticados através de coloração de rotina $(H / E)$, no Laboratório de Patologia Buco-dental da FO-UFRGS.

Das peças selecionadas, novos cortes de cinco micrômetros foram realizados e montados em lâminas para as evidenciações de citoqueratina de baixo peso molecular (Ae1 Biogenex) e de alto peso molecular (KAP Biogenex).

Usou-se a técnica imunohistoquímica tipo complexo Avidina-Biotina $(A B C)$, realizada no Laboratório de Anatomia Patológica do HCPA, obedecendo aos seguintes processos:

- xilol

- hidratação-álcool

- hidróxido de amônio

- bloqueio da peroxidase endôgena

- tripsinização

- soro normal

- anticorpo primário

- anticorpo secundário

- $\mathrm{ABC}$

- revelação DAB

- contra coloração - hematoxilina

- desidratação

- montagem

\section{Resultados}

Todos os casos selecionados apresentaram positividade às citoqueratinas de alto e baixo peso molecular.

Em quatro dos ceratocistos, a expressividade de citoqueratina de baixo peso molecular (Ae1) foi mais acentuada que a de alto peso molecular (KAP).
TABELA 1

Presença de positividade à citoqueratina de alto (KAP) e baixo (Ae1) peso molecular em ceratocistos

\begin{tabular}{ccc}
\hline CASO & KAP & AE1 \\
\hline 7915 & + & ++ \\
8145 & + & ++ \\
8458 & + & ++ \\
8478 & ++ & + \\
8588 & + & ++ \\
\hline
\end{tabular}

Outro fato a ser considerado é a observação de maior positividade na camada mais profunda do epitélio dos ceratocistos para os cortes corados com anticorpos anticitoqueratinas de baixo peso molecular (Ae1) (Figs. 2).

\section{Discussão}

Nossos achados mostraram que as células do revestimento epitelial do ceratocisto foram positivas às citoqueratinas de alto e baixo peso molecular, com variaçōes na intensidade em relação a profundidade das células.

GAO et al. $(4,5)$, utilizando outros marcadores, encontraram uma tendência à expressividade de citoqueratinas indicadoras de epitélio simples nas células suprabasais e algumas células basais. Os anticorpos para citoqueratina de epitélio não queratinizado também coraram fortemente as células suprabasais do ceratocisto. Um importante achado nesse trabalho foi a forte coloração com o uso de anticorpos monoclo-

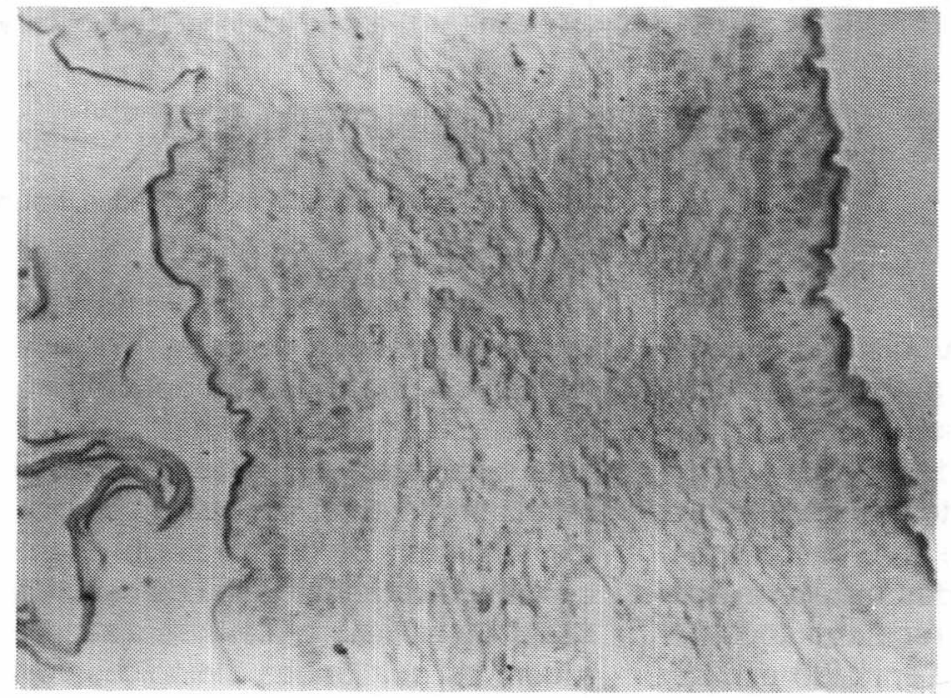

FIGURA

Observar a positividade para a citoqueratina de alto peso molecular (KAP) mais evidente junto a camada descamativa do epitélio de revestimento da cavidade cistica 50x KAP

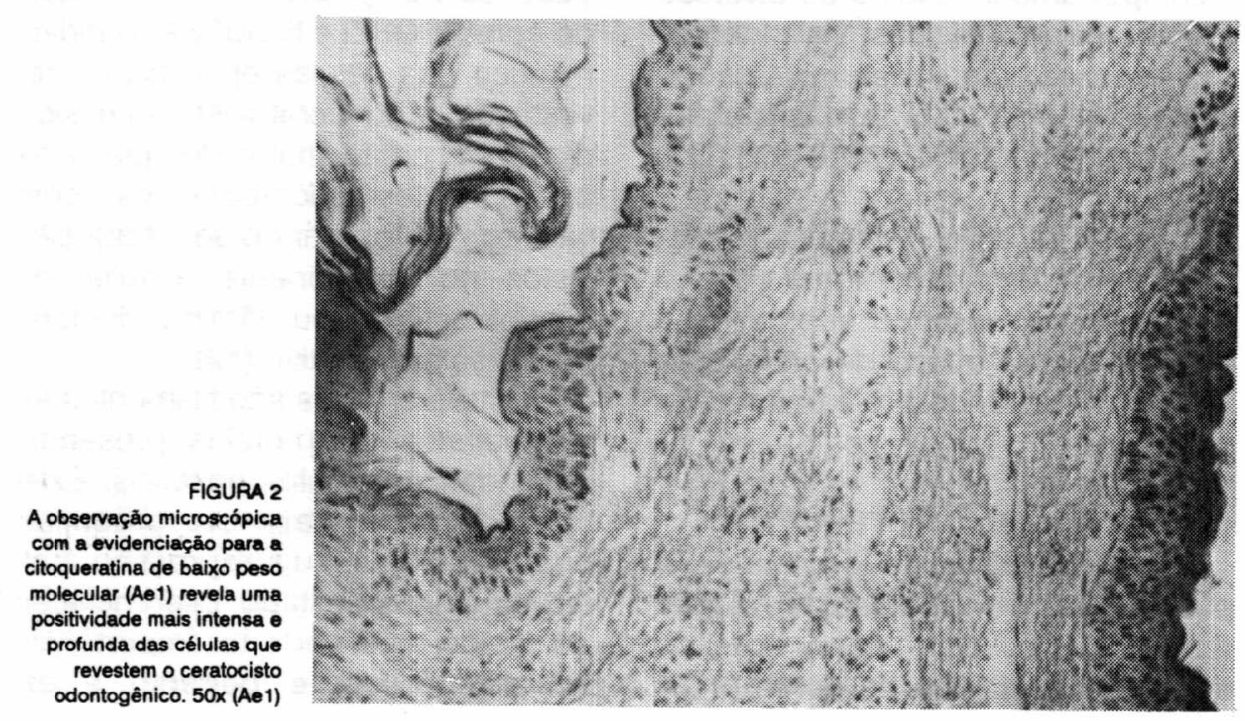

R. Fac. Odontol. 
nais contra citoqueratinas que indicam uma alta capacidade proliferativa, o que pode sugerir um alto potencial de crescimento dessas lesões. Em nosso trabalho não foi possível individualizar nenhuma dessas características, uma vez que os marcadores selecionados agruparam as citoqueratinas em dois grandes grupos de acordo com o peso molecular. Porém, observou-se claramente uma maior positividade à citoqueratina de baixo peso molecular nas camadas mais profundas do revestimento epitelial dos ceratocistos.

MATTHEWS and BROWNE (9) consideram que, embora a reatividade dos ceratocistos seja subjetivamente menos intensa que a de cistos dentígeros, esta pode estar relacionada às técnicas laboratoriais, visto que alguns anticorpos são destruídos pela fixação em formol $e$ inclusão em parafina. Apesar de utilizarmos essa técnica para conservação das peças, observamos que o epitélio foi corado pelos anticorpos anticitoqueratina de alto e baixo peso molecular. Seria necessário utilizar essa coloração em cortes realizados a partir de outras técnicas para comparar os resultados obtidos.

Concordamos com GORDEEFF e CLERGEOU (6) ao considerarem difícil a comparação de resultados devido às diferenças de protocolo $e$ materiais existentes.

Entretanto, o uso de coloraçăo imunohistoquímica tem se revelado promissor na busca de características celulares que possam explicar o comportamento biológico das lesōes e orientar as condutas de tratamento e prevenção adequadas.

\section{REFERÊNCIAS BIBLIOGRÁFICAS}

01. AGURRE, A. et al. Lectin histochemistry of ameloblstomas and odontogenic keratocysts. J Oral Pathol Med, Copenhagen, 18:66-73, 1989.

02. DONOFF, R.B., Collagenolytic activity in keratocysts. J Oral Surgery, Chicago, 30:879-884, 1972.

03. EBLING, H. et al. Cistos e tumores odontogênicos, 3 ed., Sảo Paulo, Mc GrawHill do Brasil, 1977.

04. GAO, Z. et al. Patterns of keratin-expression in rests of Malassez and periapical lesions. J Oral Pathol, Copenhagen, 17:178-185, 1988.

05. GAO, Z. et al. Cytokeratin expression of the odontogenic apithelia in dental follicles and developmental cysts. J Oral Pathol Med, Copenhagen, 18:63-67, 1989.

06. GORDEEFF, M.; CLERGEAU-GUERITHAULT, S.L. Expression de certaines cytokeratines par l'épithélium de kystes dentigères et primordiaux. L. Biol Buccale, Paris, 18:59-67, 1990.

07. KAKUDO, K. et al. Calcifying Odontogenic Cysts: co-expression of intermediate filament proteins, and immunohistochemical distribuition of keratins, involucrin and filaggrin. Path Res Pract, Stutgard, 185:891-899, 1989.

08. MAEDA, Y. Immunohistochemical study of jaws cysts: different existence of keratins in odontogenic and non-odontogenic epithelial linings. J Oral Pathol Med, Copenhagen, 19:289-294, 1990.

09. MATHEWS, J.B. Imunocytochemical methods: a technical overview. J Oral Pathol, Copenhagen, 16:189-195, 1987.

10. MORI, M. et al. Immunohistochemical expression of amelogenins in adontogenic epithelial tumours and cysts. Virchows Archiv A Pathol Anat, Berlin 418:319-325, 1991

11. RADOS, P.V. et al. Evidenciação de citoqueratina de alto e baixo peso molecular em ameloblastomas. Rev Fac Odontologia, 32:3-8, 1991.

12. REGEZI, J.A.; SCIUBBA, J.J. Patologia bucal: correlação clinicopatológica, 3 ed. Rio de Janeiro, Guanabara, Koogan, 1991.

13. SHAFER, W.G. et al. Tratado de patologia bucal, 4 ed., Rio de Janeiro, Interamericana, 1985.

vergrowths and neoplasmas. p.81-106.

14. SHEAR, M. Cysts of the jaws: Recent advances. J Oral Pathol, Copenhagen, $14: 43-59,1985$ 